\title{
Protein Kinase C Beta II (PKC ßII) Peptide Inhibitor Exerts Cardioprotective Effects in Myocardial Ischemia/Reperfusion Injury
}

\author{
Christina Lipscombe, Israel Benjamin, Devon Stutzman, Amelie Bottex, \\ Chinyere Ebo, William Chau, Harsh Patel, Qian Chen, Cathy J. Hatcher, \\ Robert Barsotti, and Lindon H. Young \\ Division of Research, Department of Bio-Medical Sciences, Philadelphia College of Osteopathic Medicine \\ (PCOM), Philadelphia, PA, 19131, USA
}

\section{Introduction}

Coronary heart disease is the leading cause of death worldwide, and is primarily attributable to the detrimental effects of tissue infarct after an ischemic insult. The most effective therapeutic intervention for reducing infarct size associated with myocardial ischemia injury is timely and effective reperfusion of blood flow back to the ischemic heart tissue. However, the reperfusion of blood itself can induce additional cardiomyocyte death that can account for up to $50 \%$ of the final infarction size. Currently, there are no effective clinical pharmacologic treatments to limit myocardial ischemia/reperfusion $(\mathrm{MI} / \mathrm{R})$ injury in heart attack patients [1]. Reperfusion injury is initiated by decreased endothelialderived nitric oxide (NO) which occurs within 5 min of reperfusion [2], and may in part be explained by PKC $\beta$ II mediated activation of NADPH oxidase, which occurs upon cytokine release during MI/R [3]. PKC $\beta$ II activity is increased in animal models of $\mathrm{MI} / \mathrm{R}$ and known to exacerbate tissue injury $[4,5]$. PKC $\beta$ II is known to increase NADPH oxidase activity in leukocytes, endothelial cells and cardiac myocytes via phox47 phosphorylation, and decrease endothelial NO synthase (eNOS) activity via phosphorylation of Thr 495 [6-8]. NADPH oxidase produces superoxide (SO) and quenches endothelial derived NO in cardiac endothelial cells. Moreover, PKC $\beta$ II phosphorylation of p66Shc at Ser 36 leads to increased mitochondrial reactive active oxygen species (ROS) production, opening of the mitochondrial permeability transition pore (MPTP), and pro-apoptotic factors leading to cell death and increased infarct size [9] (Figure 1 left). Therefore, using a pharmacologic agent that inhibits the rapid release of PKC $\beta$ II mediated ROS, would attenuate endothelial dysfunction and downstream pro-

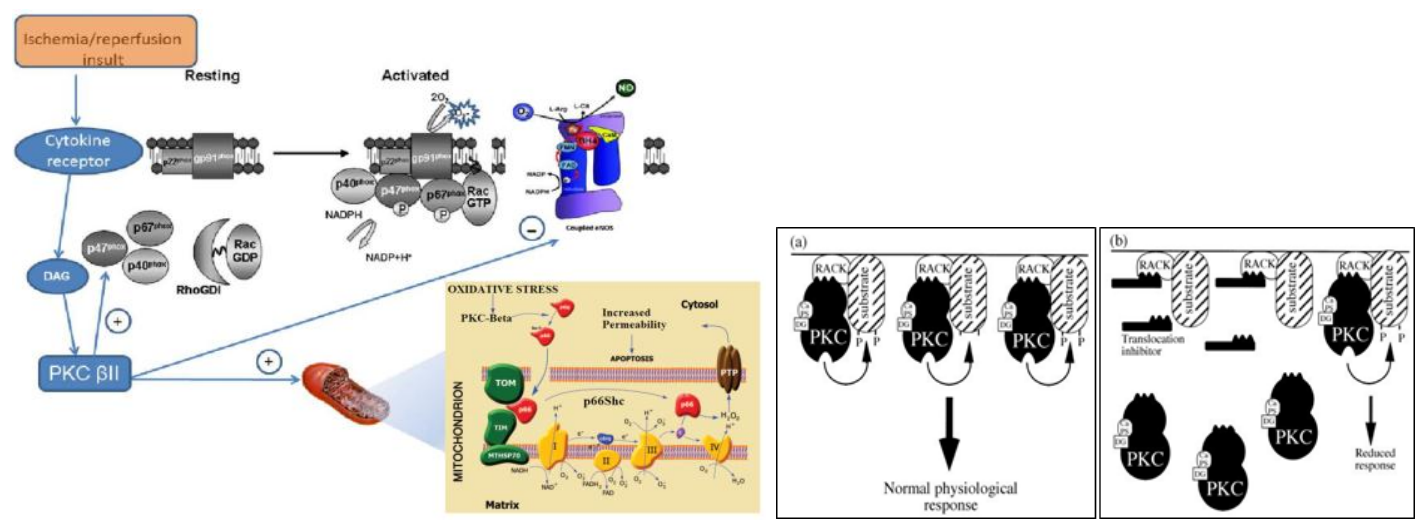

Fig. 1. Left: Schematic representation of PKC BII mediated activation in myocardial ischemia and reperfusion $(M I / R)$. MI/R induces cytokine receptor activation within minutes leading to activation of $P K C$ BII via diacylglycerol (DAG). PKC $\beta I I$ increases reactive oxygen species (ROS) release from damaged mitochondria and NADPH oxidase, respectively, and reduces coupled eNOS activity. (Adapted from [9]). Right: Mechanism of action of PKC BII peptide inhibitor. PKC BII peptide inhibitor attenuates the translocation of PKC BII to cellular substrates (e.g., NADPH oxidase) by competing for the receptor for activated $C$ kinase (RACK), adapted from [10]. 
apoptotic pathways when given during reperfusion and should be an ideal candidate to attenuate MI/R injury. PKC $\beta$ II peptide inhibitor mechanism of action (Figure 1 right) is to inhibit PKC $\beta I I$ translocation to cellular substrates such as eNOS, NADPH oxidase, and mitochondrial p66Shc protein that increase ROS leading to opening of the MPTP which in turn leads to consequent release of proapoptotic factors into the cytosol $[9,10]$. We've previously shown that PKC $\beta$ II peptide inhibitor restored post-reperfused cardiac function and reduced polymorphornuclear leukocyte (PMN) infiltration in isolated rat hearts subjected to $\mathrm{MI}(20 \mathrm{~min}) / \mathrm{R}(45 \mathrm{~min})$ reperfused with PMNs [8]. In addition, the use of PKC $\beta$ II peptide inhibitor $(10-20 \mu \mathrm{M})$ correlated with the inhibition of SO release from isolated leukocytes suggesting that this dose range maybe effective in attenuating ROS production [11].

We extended our research in the current study by using a MI (30 min)/R (90min) isolated perfused rat heart model. A cell permeable PKC $\beta$ II peptide inhibitor $(10-20 \mu \mathrm{M})$ was given at the beginning of reperfusion for five minutes. Post-reperfused cardiac function and infarct size were measured and compared to untreated control MI/R hearts.

\section{Hypothesis}

We hypothesize that PKC $\beta$ II peptide inhibitor will improve post-reperfused cardiac function and reduce infarct size in isolated perfused rat hearts (ex vivo) subjected to global MI/R compared to nondrug control MI/R hearts in MI(30min)/R(90min) studies.

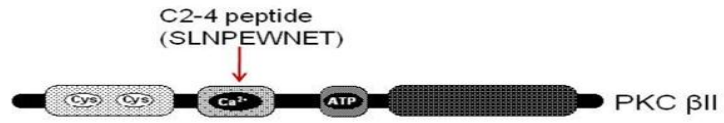

Fig. 2. PKC $\beta$ II peptide inhibitor location resides in the $\mathrm{Ca}^{2+}$ binding domain (C2-4 region) of RACK (N-Myr-SLNPEWNET), adapted from [8].

\section{Methods}

\section{Isolated Rat Heart Preparation}

Male Sprague Dawley rats (275-325g, Charles River, Springfield, MA) were anesthetized with pentobarbital sodium $(60 \mathrm{mg} / \mathrm{kg})$ and anti-coagulated with sodium heparin $(1,000 \mathrm{U})$ injection intraperitoneally. Hearts were rapidly excised and perfused at a constant pressure of $80 \mathrm{~mm} \mathrm{Hg}$ with a modified physiological Krebs' buffer aerated with $95 \% \mathrm{O}_{2}-5 \% \mathrm{CO}_{2}$ maintained at $37^{\circ} \mathrm{C}$ and $\mathrm{pH}$ 7.3-7.4 by Langendorff preparation. Hearts were subjected to $15 \mathrm{~min}$ of baseline perfusion, $30 \mathrm{~min}$ of ischemia, and a $90 \mathrm{~min}$ reperfusion period [8]. Five $\mathrm{ml}$ of plasma (control MI/R hearts), or plasma containing cell-permeable PKC $\beta$ II peptide inhibitor (N-Myr-SLNPEWNET, MW=1300 g/mol, 10-20 $\mu \mathrm{M}$ Genemed Synthesis Inc., San Antonio, TX) (Figure 2) were infused during the first $5 \mathrm{~min}$ of reperfusion by a side arm line proximal to the heart inflow at a rate of $1 \mathrm{ml} / \mathrm{min}$. Coronary flow, left ventricular developed pressure (LVDP), maximal and minimal rate of LVDP $\left(+\mathrm{dP} / \mathrm{dt}_{\max }\right.$ and $\left.-\mathrm{dP} / \mathrm{dt}_{\min }\right)$, and heart rate were taken every 5 min during baseline and reperfusion using a flow meter (T106, Transonic Systems, Inc., Ithaca, NY) and pressure transducer (SPR-524, Millar Instruments, Inc., Houston, TX), respectively. Data were recorded using a Powerlab Station acquisition system (ADInstruments, Grand Junction, CO).

Sham hearts experienced no ischemia, received no drug and were infused with plasma at the same time point as I/R hearts. To evaluate tissue viability, the left ventricle was isolated at the end of the cardiac function experiment and cross sectioned into five $2 \mathrm{~mm}$ thick slices from apex to base. The slices were subjected to $1 \%$ triphenyltetrazolium chloride (TTC) staining for $15 \mathrm{~min}$ at $37^{\circ} \mathrm{C}$ (viable tissue stained red, infarct left unstained (white)). Infarct size was expressed as the percentage of dead tissue to the total tissue weight.

\section{Statistical Analysis}

All data in the text and figures are presented as means \pm S.E.M. Analysis of variance using post hoc analysis with the Student-Newman-Keuls test was used for heart function and infarct size in the $\mathrm{MI}(30 \mathrm{~min}) / \mathrm{R}(90 \mathrm{~min})$ study. Probability values of $<0.05$ are statistically significant. 

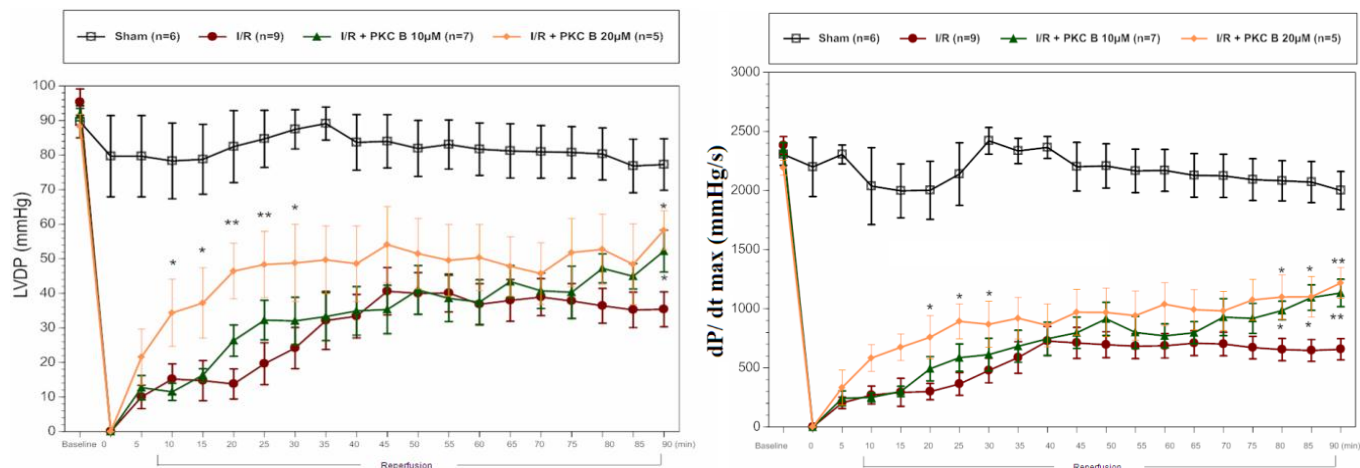

Fig. 3. Time course of LVDP (left) and dP/dt max (right) in sham, control MI/R and MI/R+PKC $\beta I I$ inhibitor (10 and $20 \mu \mathrm{M})$ perfused rat hearts. LVDP and $d P / d t$ max data at initial (baseline) and reperfusion from 0 to 90 min following 30 min ischemia are shown. $(* p<0.05 ; * * p<0.01$ compared to untreated control MI/R hearts).

\section{Results and Discussion}

This study focused on the inhibition of PKC $\beta I$ in MI/R injury. Figure 3 shows that PKC $\beta$ II inhibitor $(10$ and $20 \mu \mathrm{M})$ significantly improved cardiac function compared to untreated control MI/R hearts. Sham hearts $(n=6)$ maintained cardiac function throughout the experimental protocol (i.e., $87 \pm 9 \%$ of initial LVDP and $89 \pm 8 \%$ of initial $\left.\mathrm{dP} / \mathrm{dt}_{\max }\right)$. MI/R+PKC $\beta$ II inhibitor hearts $(10 \mu \mathrm{M}, \mathrm{n}=7 ; 20 \mu \mathrm{M}, \mathrm{n}=5)$ exhibited a significant improvement in LVDP $66 \pm 8 \%$ and $\mathrm{dP} / \mathrm{dt}_{\max } 56 \pm 8 \%(20 \mu \mathrm{M})$ and $57 \pm 7 \%$ and $48 \pm 5 \%(10 \mu \mathrm{M})$ compared to control MI/R hearts $(n=9)$ that only recovered to $38 \pm 6 \%$ (LVDP) and $28 \pm 4 \%\left(\mathrm{dP} / \mathrm{dt}_{\max }\right)$ at $90 \mathrm{~min}$ post-reperfusion of initial baseline. MI/R+PKC $\beta \mathrm{II}$ inhibitor hearts $(20$ $\mu \mathrm{M}$ ) significantly improved post-reperfused LVDP at 10-30 and 90 minutes and $\mathrm{dP} / \mathrm{dt}_{\max }$ at 20-30 and 80-90 minutes compared to untreated MI/R controls. MI/R+PKC $\beta$ II inhibitor hearts $(10 \mu \mathrm{M})$ significantly improved post-reperfused LVDP at 90 minutes and $\mathrm{dP} / \mathrm{dt}_{\max }$ at $80-90$ minutes compared
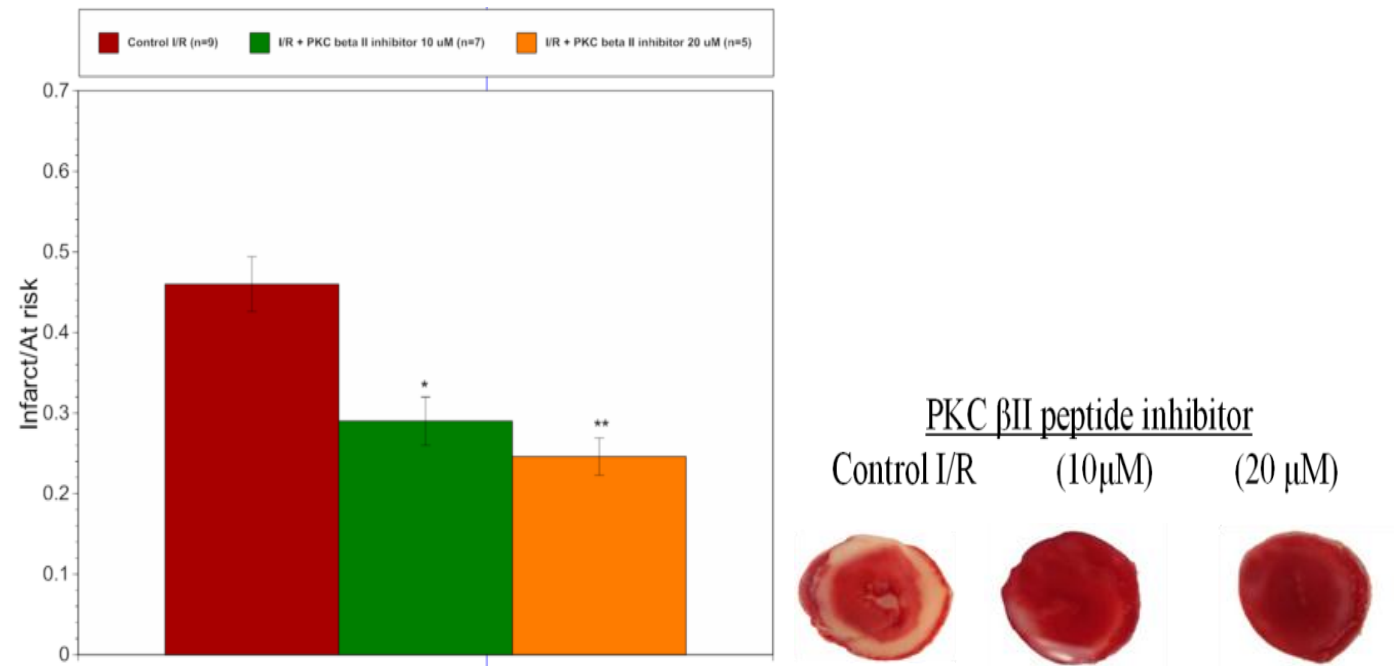

Fig. 4. Representative TTC stained heart sections displayed above from control MI/R and $M I / R+P K C \beta I I$ inhibitor hearts were assessed after cardiac function experiments to determine infarct size. Viable tissue stained red and infarcted tissue was unstained (white). $\left({ }^{*} p<0.05\right.$ and $* * p<0.01$ compared to I/R control). 
to untreated MI/R controls. Also, PKC $\beta$ II inhibitor hearts displayed a significantly reduced infarct size $(29 \pm 3 \%, 10 \mu \mathrm{M} ; 25 \pm 3 \%, 20 \mu \mathrm{M})$ and compared to untreated I/R hearts that had an infarct size of $46 \pm 3 \%$ (Figure 4). Sham hearts had minimal cell death $(<0.05 \%)$ at the end of the experimental protocol (data not shown).

In conclusion, PKC $\beta$ II peptide inhibitor was shown to improve post-reperfused cardiac function and decrease infarct size. Reperfusion injury following myocardial ischemia has been shown to be a pathologic condition resulting in contractile dysfunction and myocardial cell death in animal models and patients suffering from a myocardial infarction. PKC $\beta$ II peptide inhibitor given at the beginning of reperfusion significantly improved contractile function and decreased infarct size compared to MI/R untreated controls at $90 \mathrm{~min}$ post-reperfusion following $30 \mathrm{~min}$ global ischemia. These data suggest that PKC $\beta$ II inhibition during reperfusion attenuates MI/R injury by improving cardiac function and salvaging heart tissue. These effects may be related to inhibiting ROS release in MI/R. Therefore, PKC $\beta$ II inhibitor will be an effective therapeutic tool to ameliorate cardiac contractile dysfunction and tissue damage in heart attack, coronary bypass, and organ transplant patients.

\section{Acknowledgments}

This study was supported by the Center for Chronic Disorders of Aging and the Department of Bio-Medical Sciences at PCOM. Special thanks to PCOM DO/Biomed students Stephanie Liu, Christine Adekayode, and Gregory Stoner for assistance in the preparation of this manuscript.

\section{References}

1. Hausenloy, D.J., Yellon, D.M. J. Clin. Invest. 123, 92-100 (2013), http://dx.doi.org/10.1172/JCI62874

2. Lefer, A.M., Lefer, D.J. Cardiovasc. Res. 32, 743-751 (1996), http://dx.doi.org/10.1016/S00086363(96)00073-9

3. Frangogiannis, N.G., et al. Circulation 98, 699-710 (1998), http://dx.doi.org/10.1161/01.CIR.98.7.699

4. Kong, L., et al. Am. J. Physiol. Heart Circ. Physiol. 294, H1862-870 (2008), http://dx.doi.org/10.1152/ajpheart.01346.2007

5. Rui, T., Tang, Q. PLoS One e56089 (2013), http://dx.doi.org/10.1371/journal.pone.0056089

6. Korchak, H.M, Kilpatrick, L.E. J. Biol. Chem. 276, 8910-8917 (2001), http://dx.doi.org/10.1074/ibc.M008326200

7. Chiasson, V.L., et al. J. Pharmacol. Exp. Ther. 337, 718-723 (2011), http://dx.doi.org/10.1124/jpet.110.178095

8. Young, L.H., et al. Cardiovasc. Drug Rev. 23, 255-272 (2005), http://dx.doi.org/10.1111/j.15273466.2005.tb00170.x

9. Cosentino, F., et al. Arterioscler. Thromb. Vasc. Biol. 28, 622-628 (2008), http://dx.doi.org/10.1161/ATVBAHA.107.156059

10. Csukai, M., Mochly-Rosen, D. Pharmacol. Res. 39, 253-259 (1999), http://dx.doi.org/10.1006/phrs.1998.0418

11. Ebo, C., et al. in Srivastava, V., Yudin, A. and Lebl, M. (Eds) Proceedings of the 24th American Peptide Symposium, American Peptide Society, San Diego, 2015, in press. 